\title{
PULMONARY GAS DIFFUSION IN POLYCYTHEMIA VERA
}

\author{
By GEORGE A. HARROP, JR., AND ELMER H. HEATH
}

With the Technical Assistance of B. M. Schaub

(From the Medical Clinic, School of Medicine, Johns Hopkins University)

(Received for publication November 12, 1926)

\section{INTRODUCTION}

The cause of erythremia, or polycythemia vera, has remained a subject for speculation ever since the clinical syndrome which goes under this name was described by Vaquez in 1892 (1). Christian (2) drew attention to the fact that many of the clinical symptoms are identical with those occurring in patients with severe anemia. A more striking fact is that the symptoms very closely resemble those which are exhibited by many normal individuals after reaching high altitudes (3). The latter syndrome, which is called "mountain sickness," is now generally considered to be due to the lowered atmospheric oxygen tension. In this condition, as in erythremia, an increase in the number of red cells in the peripheral blood is a most striking pathological feature. In both diseases similar nervous symptoms occur. Osler (4) in his early paper on polycythemia stated,-_" the torpor, mental and physical; the sensation of fullness in the head, with headache, vertigo and in some cases nausea and vomiting, remind us of the symptoms to which mountain climbers and aeronauts are subject." Moreover in both conditions there may occur a similar train of visual disturbances, abnormalities of hearing, irritability, impairment of the higher mental faculties, especially memory and concentration, not infrequently insomnia, a sense of extreme weakness, particularly with unusual exertion, dyspnea, pains in the extremities, and very often attacks of syncope.

The possibility that the cause of erythremia may in some way be bound up with insufficient oxygenation of the tissues has not received much support because studies have apparently indicated no abnormality in the oxygen carrying capacity of the hemoglobin (5), and 
direct determinations of the percentage of oxygen saturation of the arterial blood in patients with polycythemia vera have yielded rather low, but still normal values. A good many determinations of the total oxygen consumption under standard conditions have shown it to be usually normal or somewhat increased. Studies of the blood gases, aside from the large oxygen content of the blood, corresponding to the increased hemoglobin content, are remarkable chiefly for the very small differences which appear to exist between the oxygen content of the arterial and of the mixed venous blood; in other words, in the low coefficient of oxygen utilization. The blood appears to contain a large mass of circulating oxygen, which remains more or less fixed in the erythrocytes and does not readily flow out into the tissues.

It was pointed out long ago by Paul Bert (6) that the physiological action of the blood gases depends upon their tension and not upon their concentration, and he predicted that the low oxygen tension existing at high altitudes would cause a polycythemia. He confirmed this prediction in 1882 upon animals living at low barometric pressures (7) and in 1890 Viault (8) first demonstrated the changes which occur in man at high altitudes. Direct determinations of the oxygen tension in freshly drawn blood have as yet been unsatisfactory in man, although the work of Krogh, who simultaneously determined the gas tensions in alveolar air and arterial blood in the rabbit (9), furnished data of great importance in clearing up the controversy concerning oxygen secretion in the lungs. Nevertheless, the shape of the dissociation curve for oxyhemoglobin indicates that relatively large differences in tension may exist with very small changes in oxygen content, so far as blood equilibrated in vitro is concerned. If we take the oxygen dissociation curve of normal blood, a difference of about twenty millimeters of oxygen tension out of a total of eighty may be found in the change from 95 to 90 per cent blood oxygen saturation. We may inquire whether an obstruction to gas diffusion, either in the diffusion through the pulmonary tissue and the alveolar wall, or through some abnormality in diffusion into the erythrocytes, may lower the oxygen tension sufficiently in certain individuals to stimulate activity of the erythropoietic tissues.

Pulmonary gas diffusion may be studied directly by the carbon monoxide method proposed by Krogh (10), and indirectly as is dis- 
cussed below, by measurement of the changes in the oxygen content of the arterial blood when the blood flow is greatly increased, as during exercise.

The principles which underlie the diffusion of gases in the lungs were formulated by Bohr (11), who suggested the use of carbon monoxide for the purpose of measurement. Practical employment of this principle was made by Krogh and Krogh (12), and the possibilities and limitations of the method for clinical use and upon untrained subjects were explored and defined by M. Krogh (10).

The method consists in measuring the diffusion of an essentially indifferent gas, carbon monoxide, which is inhaled in low concentration and mixed with the pulmonary air of the subject. Under such circumstances the gas combines practically at once with the hemoglobin, its tension in the blood in the lungs during the period of the experiment remaining so low as to be practically negligible. The determination then consists in measuring the carbon monoxide tension in the alveolar air at the beginning and end of an accurately measured interval of time. If $C_{\mathrm{o}}$ is the concentration of carbon monoxide at the beginning and $C_{\mathrm{t}}$ is its concentration at the end of the time $T$, the quantity which passes per unit volume at any moment from alveoli to blood is proportional to the carbon monoxide tension of that moment, and $\frac{\log C_{\mathrm{o}}-\log C_{\mathrm{t}}}{T \log c}=k$, which is known as the permeability and is dependent upon the permeability of the alveolar membrane for gases.

If $k$ is multiplied by the pulmonary volume, calculated at mid capacity, $(V)$, and is divided by the barometric pressure less the tension of aqueous vapor at $37^{\circ} \mathrm{C}$., $(P-p)$, we have the following expression, $\frac{k V}{P-p}=D_{\mathrm{CO}}$, which is the diffusion constant for carbon monoxide, and which may be deftned as the amount of carbon monoxide which will pass through the lungs as a whole per unit of time and per millimeter of pressure difference between alveoli and blood. On the basis of certain assumptions based on the diffusion of gases through fluids, Bohrand later Krogh-calculated from the data obtained for carbon monoxide, the diffusion constant for oxygen and other gases, which are proportional to it. The diffusion constant so calculated for oxygen, $D_{\mathrm{O}_{2}}$ has a value equal to $1.23 \mathrm{D}_{\mathrm{co}}$.

More than one hundred measurements of the diffusion constant made on twentytwo normal subjects were published by Krogh. The method was also utilized by Barcroft and his associates (13) during their Physiological Expedition to the Peruvian Andes for the study of the effects of high altitudes on man. Determinations were made upon the eight members of the expedition both at sea level and after the climb to a point at approximately fourteen thousand feet above the sea, and it appeared that the value so obtained for the diffusion constant bore a definite relationship to the severity of the symptoms of acute mountain sickness which each individual suffered in this small group. 
During the winter of 1921-1922 a systematic effort was made by one of us, with the courteous coöperation of the management of the Cerro de Pasco Copper Company to examine their employees prior to their departure for the group of mining camps of the company in the Cerro de Pasco district in the Peruvian Andes. Our object was to ascertain whether a determination of the diffusion constant might be of any prognostic value in indicating the degree of mountain sickness to which a given individual was liable. It was considered that it might be possible thus to detect individuals who were unfitted to reside for long periods at high altitudes. A preliminary report was made in 1923 (14), as the results were distinctly encouraging, but it eventually became evident that no final conclusions could be drawn without more reliable and detailed clinical observation during the period of the actual disability of the subjects examined.

Two papers have recently been published which have a bearing upon the reliability of diffusion measurements by the carbon monoxide method. One relates to the completeness with which gas mixture occurs when an inhalation is made at the end of a maximal expiration. Lundsgaard and Shierbeck (15) report that complete admixture depends on both the number and the depth of the mixing respirations, and doubts have been raised as to the completeness of gas mixture in such procedures as the present one. We do not propose now to comment on this publication or upon the technique employed or the results reported. We will, however, state that all of the determinations reported below were made after two or more deep rebreathing respirations, usually three, of at least two liters, commencing at the point of maximal expiration. The technique, therefore, was practically identical with the method adopted by Krogh and Lindhard (16) for determinations of the circulatory minute volume in man by the nitrous oxide method. The difficulty of this procedure for diffusion constant determinations lies in the fact that in the time required by the rebreathing, the rapidity of the diffusion of carbon monoxide may cause the concentration of this gas in the alveolar air to become rather low for accurate gas analysis. This practical diffculty has been overcome by using a rather high initial percentage of carbon monoxide, somewhat over one per cent, and by giving the subjects sufficient preliminary training to enable them to make the initial mixing respirations deeply and rapidly.

A second criticism may be found in the recent paper of Hartridge and Roughton (17), who conclude that the rate of combination of carbon monoxide with hemoglobin is not as rapid as had been previously assumed. It is necessary, for the purpose of the diffusion constant determination, that the combination be sufficiently rapid to make the tension of the gas in the blood practically negligible. If this is not so, and particularly if experiments are made in too rapid succession, so that the tension of the gas in the blood becomes considerable, appreciable error may result. We have taken great pains to avoid repeated determinations, and all of the data reported below are based on experiments which are either the first experiment or the sole experiment of the day. 
STUDIES OF THE DIFFUSION CONSTANT IN POLYCYTHEMIA VERA

In view of the clinical similarity between the symptoms of polycythemia and those of cerebral anoxemia, particularly as manifested in residents at high altitudes, the writers have undertaken a study of the diffusion constant in seven patients with polycythemia vera. The clinical protocols of these cases may be found at the end of this paper. The determinations were made in the sitting position, at rest, and are summarized in table 2, which shows for each individual the average permeability $(k)$ and the average diffusion constant for oxygen $\left(D_{\mathrm{O}_{2}}\right)$, as calculated at the normal mean capacity of the lungs. Each of these

TABLE 1

Summary of published normal values for the permeability and diffusion constant

\begin{tabular}{|c|c|c|c|c|c|c|}
\hline & \multicolumn{3}{|c|}{$K$ (permeability) } & \multicolumn{3}{|c|}{$\begin{array}{l}D_{\mathrm{O}_{2}} \text { (diffusion constant } \\
\text { for oxygen) }\end{array}$} \\
\hline & $\begin{array}{l}\text { Maxi- } \\
\text { mum }\end{array}$ & $\begin{array}{l}\text { Mini- } \\
\text { mum }\end{array}$ & $\begin{array}{c}\text { Mean } \\
\text { average }\end{array}$ & $\begin{array}{l}\text { Maxi- } \\
\text { mum }\end{array}$ & $\begin{array}{l}\text { Mini- } \\
\text { mum }\end{array}$ & \begin{tabular}{|l} 
Mean \\
average
\end{tabular} \\
\hline $\begin{array}{l}\text { Seventeen normal adults }(\text { Krogh })-\text { men and } \\
\text { women } \ldots \ldots \ldots \ldots \ldots \ldots \ldots \ldots \ldots\end{array}$ & 8.0 & 5.0 & 7.3 & 43.3 & 27.1 & 35.6 \\
\hline $\begin{array}{l}\text { Eleven normal adults* (Barcroft et al.) }- \\
\text { men } \ldots \ldots \ldots \ldots \ldots \ldots \ldots \ldots \ldots \ldots \ldots\end{array}$ & 8.2 & 5.4 & 7.5 & 45.6 & 25.4 & 40.6 \\
\hline
\end{tabular}

* It should be noted that the eleven adults measured by Barcroft and his associates were males whereas among Krogh's subjects were several women, who in general have slightly lower diffusion constants than men, when compared per unit of surface area.

figures is the mean of at least two determinations upon each patient made upon different days.

For comparison with the above data we have recalculated the average figures for normal individuals as found by Krogh, and by Barcroft and his associates.

As is known, the pulmonary permeability in children is in general considerably greater than in adults, which compensates for the smaller lung capacity in young individuals, and causes the diffusion constant, when calculated per square meter of body surface, to be approximately the same as that of the adult. We have, therefore, taken only the figures for adults, giving the maximum, minimum, and average figures to afford a comparison with the cases of erythremia, all in adults, studied as shown in table 2 . 
It will be noted that the results of all of the determinations of the permeability $(k)$ in the cases of polycythemia are much below the mean average of the normal cases as published in the literature, and that the diffusion constants as well are much below the mean average, and in all but two instances below the minimum values found in the twenty-eight normal cases. The diffusion of gas through the lungs is determined by two factors, the permeability and the mean capacity of the lungs, and the diffusion constant is directly proportional to both. In none of the above cases of erythremia is the total lung volume or the mid capacity abnormally low. Indeed, the residual air (and hence the mid capacity) in most of the cases comprises an unusually

TABLE 2

Lung measurements and diffusion constant determinations in cases of erythremia

\begin{tabular}{|c|c|c|c|c|c|c|c|c|}
\hline \multirow{2}{*}{$\begin{array}{c}\text { Case } \\
\text { number }\end{array}$} & \multirow{2}{*}{ Sex } & \multirow{2}{*}{ Age } & \multirow{2}{*}{$\begin{array}{c}\text { Total } \\
\text { capacity }\end{array}$} & \multirow{2}{*}{$\underset{\text { air }}{\text { Residual }}$} & \multirow{2}{*}{$\begin{array}{c}\text { Residual } \\
\text { air in } \\
\text { percentage } \\
\text { of total } \\
\text { capacity }\end{array}$} & \multicolumn{3}{|c|}{ Measurements at mean capacity } \\
\hline & & & & & & $K$ & $D_{\mathrm{co}}$ & $D_{\mathrm{O}_{2}}$ \\
\hline & & & liters & liters & per cent & & & \\
\hline 1 & F. & 52 & 4.34 & 1.59 & 36.6 & 5.7 & 20.8 & 25.6 \\
\hline 2 & F. & 59 & 3.66 & 1.47 & 40.1 & 4.6 & 18.1 & 22.3 \\
\hline 3 & M. & 38 & 5.25 & 1.38 & 26.3 & 5.3 & 18.9 & 23.2 \\
\hline 4 & F. & 52 & 4.43 & 1.48 & 33.4 & 4.2 & 14.2 & 17.5 \\
\hline 5 & M. & 42 & 6.07 & 1.61 & 26.5 & 5.0 & 23.2 & 28.5 \\
\hline 6 & M. & 48 & 4.89 & 2.06 & 42.1 & 4.6 & 19.8 & 24.4 \\
\hline 7 & F. & 50 & 3.48 & 1.27 & 33.4 & 6.1 & 17.0 & 20.9 \\
\hline
\end{tabular}

large percentage of the total capacity, as shown in table 2, and tends toward the relation which exists in pulmonary emphysema. The abnormality, therefore, in these cases is due not to reduction in pulmonary volume, but to a lowered permeability which must depend either upon a reduced area of alveolar diffusing surface, or upon the thickness and individual peculiarities of this membrane. Possible alterations of a like nature may exist, it is true, in the walls of the pulmonary capillaries or in the red blood cell membrane. Through all of these three barriers the oxygen (or carbon monoxide) from the lungs must penetrate in order to effect its combination with the hemoglobin. 
THE EFFECT OF EXERCISE UPON THE ARTERIAL OXYGEN IN POLYCYTHEMIA VERA

The effect of an increased circulation rate and an increased oxygen consumption upon the oxygen saturation of the arterial blood, depends

TABLE 3

The effect of exercise on the oxygen capacity and saturation of the arterial blood in erythremia

\begin{tabular}{|c|c|c|c|c|c|}
\hline & Pulse & $\begin{array}{l}\text { Respi- } \\
\text { ration }\end{array}$ & $\mathrm{O}_{\substack{\text { capac- } \\
\text { ity }}}$ & $\left|\begin{array}{c}\mathrm{O}_{2} \\
\text { content }\end{array}\right|$ & $\mid \begin{array}{c}\mathbf{O}_{\mathbf{2}} \\
\text { satura- } \\
\text { tion }\end{array}$ \\
\hline $\begin{array}{l}\text { Patient I: } \\
\text { Observations at rest...................... } \\
\text { (Stationary running and hopping for } 7 \text { minutes. } \\
\text { Patient became quite cyanotic and short of } \\
\text { breath and exercise was terminated because of } \\
\text { extreme weakness and vertigo) }\end{array}$ & 72 & 14 & $\begin{array}{c}\begin{array}{c}\text { ool. } \\
\text { per cent }\end{array} \\
26.7\end{array}$ & $\begin{array}{c}\text { ool. } \\
\text { per cent } \\
24.1\end{array}$ & $\begin{array}{c}\text { per cent } \\
91\end{array}$ \\
\hline Observations immediately after exercise....... & 136 & 34 & 26.3 & 23.5 & 89 \\
\hline $\begin{array}{l}\text { Patient } V \text { : } \\
\text { Observations at rest.................... } \\
\text { (Riding bicycle ergometer for } 8 \text { minutes. Color } \\
\text { of face and hands became much deeper, and } \\
\text { patient became quite short of breath. Did } \\
\text { not feel marked fatigue) }\end{array}$ & 76 & 16 & 29.1 & 27.1 & 93 \\
\hline Observations immediately after exercise...$\ldots$. & 140 & 38 & 29.1 & 25.4 & 87 \\
\hline $\begin{array}{l}\text { Patient VI: } \\
\text { Observations at rest....................... } \\
\text { (Vigorous bending and hopping for } 5 \text { minutes. } \\
\text { Moderate cyanosis of lips, considerable short- } \\
\text { ness of breath, weakness and vertigo) }\end{array}$ & 76 & 16 & $\mid 22.4$ & 21.3 & 95 \\
\hline Observations immediately after exercise... & 120 & 30 & 22.2 & 20.1 & 90 \\
\hline
\end{tabular}

on the rate at which oxygen can diffuse from the pulmonary alveoli into the blood. The increased pulmonary ventilation during exercise will raise the alveolar oxygen tension, but will not suffice to supply the amounts required if the area of diffusing surface is not great 
enough, or if the diffusion through that surface is not sufficiently rapid. The matter can be tested by direct measurement of the arterial oxygen saturation during or immediately following severe exercise. Earlier experiments (18) seemed to indicate that during exercise in man the arterial blood may not become completely saturated. The recent study by Himwich and Barr (19) however, has indicated that in normal man, the arterial blood is as completely saturated with oxygen during exercise as during rest. The saturation is, indeed, often appreciably augmented, notwithstanding the fact that there is at the same time a decided increase in the oxygen capacity.

If we may assume that an impairment of pulmonary permeability exists in some cases of erythremia, as is indicated above, then it is quite possible that exercise in these patients, instead of increasing the arterial oxygen saturation, will diminish it. Such studies have been made on three patients with erythremia, and the results are recorded below.

It will be seen that in all of the three cases in which complete studies could be made, no increase in the percentage saturation of the arterial blood took place, and that in two a drop occurred, well beyond the limit of experimental error. ${ }^{1}$

The question may be asked as to whether the slowed diffusion of gases in these cases of polycythemia vera may not in some way be due to the high erythrocyte count in the blood itself. The writers think not because of the following considerations. The available evidence ${ }^{2}$ indicates that a low circulatory minute volume occurs in this disease. This slowing of the pulmonary circulation should favor oxygen diffusion in the lungs, because a longer average loading time is afforded

${ }^{1}$ The blood oxygen determinations were made with the Van Slyke constant volume blood gas apparatus. The figures quoted in table 3 represent the average of duplicate determinations, the maximal difference in which did not exceed 0.2 vol. per cent. (Van Slyke and Neill, J. Biol. Chem., 1924, lxi, 523.)

2 The early studies on the blood flow in polycythemia are unsatisfactory and contradictory. Haldane suggested that a retarded circulation must be present, a view for which support may, be found in the marked peripheral stasis shown to be present, notably by Brown and Giffin (23), and in the plethora found by various authors. Liljestrand and Stenström (24) in carefully controlled studies with the Krogh-Lindhard nitrous oxide method have,demonstrated considerable reduction 
per corpuscle for taking up its moiety of oxygen. The increased proportion of corpuscle volume to plasma will make a shorter distance between capillary wall and erythrocyte membrane for the diffusing gas to travel and will provide an increased area of red blood cell surface through which to penetrate. From the study of the following case, there seems to be no significant change in diffusion of oxygen as a result of reduction in the number of erythrocytes and in the hemoglobin concentration.

Case VII when first seen had an erythrocyte count in the peripheral capillary blood (finger) of 8.4 million and in the venous blood of 8.1 million. Following two and one-half months of intensive phenylhydrazine and radium therapy, marked diminution in the erythrocyte count occurred, so that a temporary period of anemia resulted, the erythrocytes being 3.9 million in the finger blood and 4.0 million in the venous blood. Determinations of the diffusion constant were made before and after this treatment with the following results:

\begin{tabular}{l|c|c|c|c}
\hline & $\begin{array}{c}\text { RBC (per cubic } \\
\text { millimeter) } \\
\text { (Finger blood) }\end{array}$ & Capacity & \multicolumn{2}{|c}{$\begin{array}{c}\text { Measurements at mean } \\
\text { capacity }\end{array}$} \\
\cline { 2 - 5 } & & $K$ & $D_{\text {CO }}$ \\
\hline million & vol. per cent & & \\
Before treatment.............. & 8.4 & 27.8 & 6.1 & 17.0 \\
After treatment............. & 4.0 & 12.2 & 5.9 & 16.7 \\
\hline
\end{tabular}

The diffusion constant was not altered, notwithstanding the change in the red cell count. We are obliged, therefore, to conclude that the slow diffusion in this case is due to causes within the lung itself and not to the altered concentration of the blood circulating through it.

of the circulation rate in one case. Serial determinations, to be published elsewhere, of the blood flow in an individual suffering from erythremia, under standard conditions of metabolism and posture during a course of treatment which reduced the polycythemia from eight to four and a half million red cells, showed a corresponding and coincident rise in the circulatory minute volume.

This increased blood flow may have an important effect at the periphery. The stagnation will be lessened, and the rate of flow through the peripheral capillaries will be increased. The blood, though containing less oxygen and with a lowered oxygen capacity, may, with an increased rate of flow, deliver that oxygen to the tissues at a higher average pressure. 


\section{DISCUSSION}

At the present time the following opinions concerning erythremia appear to be widely held (20). It seems to be accepted that there is a constant increase, often very great, in the number of erythrocytes in the circulating blood, except during the periods when it is reduced by medical measures. These erythrocytes are essentially normal in their morphology and physiological behavior. There is a corresponding increase in the concentration of hemoglobin, which is also quite normal, at least so far as its oxygen carrying function is concerned. The blood volume appears to be increased, the blood viscosity is increased in proportion to the degree of erythrocytosis, and the blood flow, if altered, is probably diminished. The proposition is apparently accepted that the blood contains an amount of available oxygen greatly in excess of all tissue needs, and that therefore less than the normal amount is given off per unit of blood, although at the same time great stagnation occurs in the capillaries throughout the viscera and certainly at the periphery. Nevertheless, with all of this excess of supposedly available oxygen, many of the clinical symptoms clearly resemble those of cerebral anoxemia. The outstanding and constant pathological finding, aside from the generally increased blood content of the viscera, is the hyperplasia and hyperfunction of the erythropoietic tissues, a condition which can be reproduced in animals subjected to a low oxygen tension. As far as the heart and lungs are concerned, some degree of pulmonary emphysema and chronic bronchitis is very common, although not a constant autopsy finding, and dilatation of the left heart and moderate cardiac insufficiency is frequent, but by no means invariable.

The possibility that structural peculiarities of the pulmonary epithelium may exist, not directly related to circulatory disturbances, which are of such a nature that they may impede the pulmonary diffusion of gases in polycythemia vera is not inherently improbable. There is some evidence that a lowered functional capacity of the lungs for gas diffusion may be an inherited characteristic, occurring in other individuals of the same family. On the other hand, recent papers emphasize more and more the familial tendency of many cases of erythremia (21). When specific search has been made, high ery- 
throcyte counts and splenomegaly have been reported in relatives who suffer from no lack of well being whatever.

On the other hand, an inspection of the published data and a consideration of established clinical facts indicates that individuals vary widely as to the extent to which increases in erythrocyte count and hemoglobin are produced by exposure to low oxygen tensions. The degree of erythrocytosis which is produced in conditions of chronic dyspnea caused by pathological changes in the circulatory and respiratory organs is known to vary considerably in different individuals, and the same variable response is found in normal persons subject, at high altitudes, to a low oxygen tension. That the duration of the exposure has an effect is readily seen in the three groups of individuals studied by Barcroft and his party at Cerro de Pasco. The recent arrivals (two weeks) had the smallest average increase above normal, the group of white residents who had lived at high altitudes for a year or more had a greater response, while the natives, who had lived all their lives in the high Andes, exhibited, on the average, the highest red cell counts and hemoglobin concentrations of all. The studies which have been made upon animals also indicate wide individual variation in the erythropoietic response to a given lowering of oxygen pressure (22).

It is becoming increasingly evident that the disease, erythremia, or rather an erythrocytosis which precedes it, is likely to have been present for a long time before it finally obtrudes itself upon the consciousness of the patient. Cases are cited of individuals who have applied to their physician for cosmetic reasons, to be rid of the unnatural red flush of the skin-"mehr rot als krank" - and who are otherwise symptom free. The malady is one of middle life, when the development of secondary lung changes, fibrosis or emphysema, or of mild circulatory changes, or of hypertension, or of arteriosclerotic changes in the brain, may be the culminating event which finally impresses on the mind of the sufferer the consciousness of a serious disorder. Nervous symptoms are among the most common for which medical advice is sought, and it is these symptoms which are common in mild grades of chronic anoxemia.

It is, of course, possible that the slowed rate of diffusion of gas through the pulmonary epithelium, which we have shown to exist in these cases of polycythemia, may not be a causal factor, but after all, 
an effect. The possibility exists that the marked engorgement of the lungs with blood over a long period, a condition which these organs share in common with all of the other viscera, may produce alterations, structural or functional, the importance of which upon pulmonary gas exchange we have no means of estimating. Studies of diffusion in heart and lung diseases, owing in large part to the technical difficulties, have been meager and the results rather uncertain, but in the cases which Krogh reports of asthma and pulmonary emphysema, no marked changes in the diffusion were observed.

Comment must be made upon a final point. We have stated that reduction of the erythrocyte count and hemoglobin does not appear to alter the rate of pulmonary gas diffusion. How then can we account for the clinical improvement which often follows therapy directed to this end? The writers are inclined to attribute it to the reduction in the abnormally high blood viscosity, which appears to be associated in this disorder with a diminished blood flow, and to the resulting improvement in the circulation and in the supply of oxygen at a higher tension at the periphery.

\section{SUMMARY}

1. Attention is drawn to the fact that although the blood in patients with polycythemia vera carries an amount of oxygen greatly in excess of that in normal blood, the symptoms in many respects resemble closely those produced by chronic anoxemia, particularly as seen at high altitudes.

2. The slow insidious development of the symptomatology of the syndrome, the probable long standing antecedent polycythemia, the familial tendency of certain investigated cases, and the appearance of the disease as a disabling condition usually late in middle life, point to the cumulative effects of a long standing or inherited physiological fault.

3. Evidence is presented to show that some functional obstruction exists in the lungs which lowers the pulmonary permeability for gases.

4. Substantiating evidence is presented to show that where the pulmonary diffusing mechanism is put to a test, as in the increased blood flow during severe exercise, the oxygen content of the arterial blood falls, whereas in the normal individual it is increased. 
5. The disease cycle in these cases is pictured as follows: There is an obstruction to the pulmonary diffusion of oxygen which produces a lowered oxygen tension in the bone marrow, and causes an increased erythrocyte production. The resulting polycythemia, probably chiefly by reason of the increased viscosity of the blood, diminishes the blood flow. This diminished blood flow, together with the lowered oxygen tension of the blood, produces a certain grade of anoxemia which manifests itself especially in the brain and nervous tissues. The clinical improvement following reduction of the polycythemia and the coincident lowering of the blood viscosity, is produced by the increased blood flow at the periphery.

Case I. E. M. C., female, age 52, housewife. Admitted J. H. H., February 19, 1926. Discharged April 19, 1926.

Family and past histories have no obvious bearing on present condition.

Onset of symptoms dates from June, 1918, when she was thought to be "white" and "pale." A physician called her anemic and prescribed iron. A year later she was observed to have purple lips and her friends remarked that her face had become flushed. At the same time she commenced to have severe headaches, vertigo and fullness in the head, and bright spots before the eyes. Examination by a physician in 1920 showed an erythrocyte count of 8.0 million. Her symptoms continued as above described, and later on she had attacks of hematemesis, bloody diarrhea and epistaxis. For the past eighteen months she has been especially troubled with roaring in the ears and head, with severe visual disturbances and there have been several syncopal attacks preceded by prodromal roarings in the ears, dizziness and dimness of vision. She has become "clumsy," and falls easily. There have been numerous paresthesias - tingling of the fingers and toes, numbness in the extremities, a burning sensation over the soles of the feet, and fleeting pains in the arms and legs. There has been loss of memory and increasing emotional instability. She has had extensive treatment with phenyl hydrazine, recently in large doses, as the drug has clearly grown less effective in lowering the erythrocyte count. There have also been repeated venesections and two radium treatments. The erythrocyte count has fluctuated with treatment during the course of the disease, the highest count, in June 1925, being 11.5 million.

Physical examination, February 1926, reveals a fairly well nourished and developed woman with dusky red flush to face, neck and hands. The lips, tongue and mucous membranes are a dark intense red. The heart and lungs reveal no particular abnormalities. B.P. 138/86. The spleen is enlarged, about three fingers below the rib margin. The liver is not felt.

Blood examination, February 28, 1926. R.B.C. 9.7 million. W.B.C. 27,000.

Blood examination, July 7, 1926 (at end of period of observation). R.B.C. 6.1 million (vein); 6.2 million (finger). 
Case II. B.U.C., female, age 59, housewife. Admitted J. H. H., May 19, 1926. Discharged June 15, 1926.

Family history. She comes of a family in which obesity is common.

Past history is negative except that the patient has always been obese, weighing at the maximum, fifteen years ago, 220 pounds.

Onset of symptoms has been gradual. Five years ago she began to suffer from headache, roaring in the ears, vertigo and occasional epistaxis, some blurring of vision, and on one occasion temporary blindness. She was told then that she had high blood pressure. About a year ago the left great toe became very tender and painful with burning sensations, and a few months later the great toe on the other side was similarly affected. The process spread to the other toes-severe burning and reddening, intermittent, relieved by cold applications and elevation, aggravated by heat and lowering.

Physical examination, May 1926, shows a moderately obese woman. There is nothing very striking in the color of the face or chest. The mucous membranes are engorged-cyanotic rather than erythremic. The toes are bluish in color with marked color changes on application of heat or cold, or upon change in position. The heart and lungs show no striking abnormality. B.P. 185/110. There is moderate peripheral arteriosclerosis. The spleen is felt just below the costal margin. X-ray of chest shows slight enlargement of the left cardiac border.

Blood examination. R.B.C. 7.7 million (finger); 8.2 million (vein). W.B.C. 28,000 .

With three courses of phenyl hydrazine the symptoms in the feet were greatly relieved and the erythrocyte count became normal.

Case III. J. T., male, age 38, fireman. Admitted J. H. H., April 4, 1923. Discharged April 17, 1923.

Family and past history negative.

Symptoms of the present disease began about five years ago with attacks of dimness of vision, especially in the right eye, numbness in the arms and legs, dizziness, insomnia, weakness, and thickness of speech. There has also been a sensation of fullness in the head, tinnitus, occipital headaches, and pain in the abdomen with occasional vomiting, and shortness of breath on exertion. A year, or even two years prior to the definite onset of the above symptoms, however, he had noticed that his skin was becoming increasingly red.

He was admitted to the hospital in April 1923, with the typical color of erythremia, dilatation of veins in pharynx and fundi, and a palpable spleen. B.P. $190 / 110$.

Blood examination. R.B.C. 8.7 million. W.B.C. 11,300 .

The erythrocyte count at this admission reached as high as 9.4 million. He was given several venesections and radiation once.

He has been seen frequently since in the Out Patient Department and returned for observation and study in May, 1926. He has been able to do some light work and in general his symptoms have improved. 
Case IV. C. E., female, age 52, housewife. Admitted J. H. H., December 8, 1925. Discharged February 20, 1926.

Family and past history negative.

Onset about six years ago with shortness of breath and dizziness especially on exertion. Abouit a year later she complained of pain in the chest and arms, morning headaches, attacks of abdominal pain and swelling, and redness and pain in the fingers and toes especially on the left side. During the past year she has had palpitation, one attack of severe pain in the left side, and several attacks of numbness of the arms and legs. There has been some dimness of vision. She has felt dull and her memory has grown poor.

Physical examination, December 1925, shows moderate cyanosis of lips and face. The chest is slightly emphysematous with some cardiac enlargement. B.P. 180/105. The measurements of a teleoroentgenogram of the heart are M.R. $4.5 \mathrm{~cm}$., M.L. $10 \mathrm{~cm}$. The eye grounds show moderately engorged veins. The spleen is palpable and the liver edge just felt. There is moderate peripheral arteriosclerosis.

Blood Examination, December, 1925. R.B.C. 8.6 million. W.B.C. 9,200. Arterial oxygen saturation $22.65 / 25.5=89$ per cent.

With phenyl hydrazine treatment and venesection the R.B.C. dropped to 4 million, and the pains in the arms and legs improved. At the period of this study (May, 1926) the blood showed R.B.C. 5.7 million and W.B.C. 10,000.

Case V. R. F., male, age 42, teacher. Referred for study by Rockefeller Hospital, New York City.

Family history. The father had a florid complexion when younger, but a recent blood count was normal.

Past history. The patient has always had a ruddy complexion, undoubtedly above normal.

Onset about 7 years ago when he was disturbed by transient bright specks in both fields of vision, later diplopia, vertigo, nausea and vomiting-at times projectile-transient paresthesias, transient aphasia and loss of memory, "thickness" of speech, and difficulty in the association of ideas. There have been occasional aches and pains in the extremities, usually not lasting, and infrequent occipital headache. About eighteen months ago there was a sense of fullness noted in the left side due to enlargement of the spleen.

Physical examination, May 1926, reveals a well nourished man with very dusky reddish skin and tortuous engorged temporal veins. The eye grounds show marked deepening of the general retinal color with thick distended veins, and general vascular engorgement. The mucous membranes, tongue and lips are dusky red. The lungs and heart are clear and the $x$-ray shows no abnormalities. The liver edge is felt below the costal margin and the spleen, firm but not tender, descends two fingers below the rib border. B.P. 130/100. The erythrocyte count in the past two years has been as high as 12.9 million. There have been numerous courses of phenyl hydrazine. He has also received X-ray treatments and venesection.

Blood examination. R.B.C. 7.3 million (vein); 7.5 million (finger). 
Case VI. C. R. J., male, age 48, laborer. Referred for study through the courtesy of Dr. Thomas R. Boggs.

Family and past histories are negative.

Onset of symptoms in the spring of 1924 with pain across the shoulders and lower back; progressive weakness and loss of weight; occasional nausea with vomiting; dizziness, headache and occasional vertigo. He was first observed at Bay View Hospital in November, 1924, at which time in the physical examination it was noted that there were dilated blood vessels over the face and forehead, the chest was emphysematous in type, the heart was not enlarged. B.P. 120/80. There was a very large and rather firm spleen. The erythrocyte count was 7.2 million and the leucocytes 34,000 . During the next eighteen months he received a number of courses of phenyl hydrazine in doses of from 0.1 to 0.2 gram per day. The erythrocytes on several occasions rose to 8.5 million. The blood pressure appears to have risen progressively following the first observation and in March, 1926 the mean of several observations was 200/120. Recently, phenyl hydrazine therapy has had decidedly less effect on the erythrocyte count than during the first months of treatment.

Status praesens, June 1926, reveals a man of medium stature with evidence of considerable undernutrition. There are many dilated venules on the nose and cheeks, the ears and lips are bluish red, and the dark color is very striking over the tongue, mucous membranes and conjunctivae. The finger tips are distinctly cyanotic rather than red. The eye grounds show marked venous engorgement. The chest is moderately emphysematous. The heart is somewhat enlarged to the left, the border percusses $14 \mathrm{~cm}$. from the mid line at the fifth interspace. B.P. $158 / 100$. There is well marked peripheral arteriosclerosis with especial thickening of the radial and brachial arteries. The spleen is very large, extending $4 \mathrm{~cm}$. below the umbilicus, firm and not tender. The liver edge is distinctly felt just below the costal angle.

X-ray examination of the chest (Dr. Baetjer) showed the teleoroentgenogram measurements of the heart to be M.R. $6 \mathrm{~cm}$., M.L. $10.5 \mathrm{~cm}$. The chest x-ray plate showed the heart and aorta a trifle enlarged and an emphysematous type of chest.

Blood examination. R.B.C. 7.07 million (finger); 7.4 million (arm vein).

Case VII. S. S., female, age 54, housewife. Referred for study through the courtesy of Dr. H. M. Thomas, Jr.

Family history. The patient has one brother who has always had a high color. (An examination of this relative has not been possible.)

Past history. The patient has been distinguished by her ruddy complexion since childhood. Her ears and nose have been especially deeply colored, so that she has been teased as being "rummy." This color has always been much worse on exertion.

Onset was insidious with hot flushes 7 or 8 years ago at the commencement of the menopause period. Later she had increasing weakness, fullness in the head 
and giddiness, headache behind the eyes, and pains in the back and legs, with numbness and burning sensations in the feet and hands. She was told by a physician 5 years ago that she had hypertension. A year ago she had a sudden. attack of vertigo followed by unconsciousness and there have been six or seven more such episodes since. She has had palpitation and shortness of breath on exertion. Her memory has become very poor, she cannot concentrate, and she has become increasingly nervous and irritable. She has lost seventeen pounds in weight in the past 6 years. During the course of the past five months she has had two courses of phenyl hydrazine and several radium treatments.

Physical examination shows a woman with ruddy complexion, deeply colored lips, tongue, and mucous membranes. There is evidence of moderate loss of weight. The heart is not enlarged and the sounds are normal. Teleoroentgenogram measurements are M.R. $4 \mathrm{~cm}$. and M.L. $9.5 \mathrm{~cm}$. The lungs are clear but hyperresonant. The $\mathrm{x}$-ray indicates an emphysematous type of chest. B.P. $170 / 110$. Very moderate peripheral arteriosclerosis. There is a firm palpable spleen descending two fingers' breadth and the liver edge is felt. The hands and feet are negative.

Blood examination. R.B.C. 8.4 million (finger); 8.1 million (vein).

We wish to acknowledge the kindness of Dr. T. R. Boggs, Physician in Chief, Bay View Hospital; Dr. H. M. Thomas, Jr.; and the Rockefeller Hospital, New York, for giving us the opportunity of studying patients.

\section{BIBLIOGRAPHY}

1. Vaquez, H., Bull. méd., Paris, 1892, vi, 849. Sur une forme spéciale de cyanose s'accompagnant a'hyperglobulie excessive et persistante.

2. Christian, H. A., Med. Clin. N. A., 1925, viii, 1403. Some Clinical Similarities between Patients with Pernicious Anemia and Those with Polycythemia.

3. Barcroft, J., Respiratory Function of the Blood. Part I. Lessons from High Altitudes. Cambridge, 1925.

4. Osler, W., Am. J. Med. Sci., 1903, cxxvi, 187. Chronic Cyanosis with Polycythaemia and Enlarged Spleen: A New Clinical Entity.

5. Butterfield, E. E., Zeitschr. f. physiol. Chem., 1909, lxii, 173 . Über die Lichtextinktion, das Gasbindungsvermögen, und den Eisengehalt des menschlichen Blutfarbstoffs in normalen und krankhaften Zuständen.

6. Bert, Paul, La pression barometrique, recherches de physiologie expérimentale. Paris 1878.

7. Bert, Paul, Compt. rend. de l'Acad. d. Sci., 1882, xciv, 805-807. Sur la richesse en hémoglobine du sang des animaux vivant sur les hauts lieux.

8. Viault, M., Compt. rend. de l'Acad. d. Sci., 1892, cxiv, 1562. Action physiologique des climats de montagne.

9. Krogh, A., and Krogh, M., Skand. Arch. f. Physiol., 1910, xxiii, 179. On the Tensions of Gases in the Arterial Blood. 
10. Krogh, M., Jour. Physiol., 1915, xlix, 271. The Diffusion of Gases Through the Lungs of Man.

11. Bohr, C., Skand. Arch. Physiol., 1909, xxii, 244. Úber die spezifische Tätigkeit der Lungen bei der respiratorischen Gasaufnahme und ihr Verhalten zu der durch die Alveolarwand stattfindenden Gasdiffusion.

12. Krogh, A., and Krogh, M., Skand. Arch. f. Physiol., 1910, xxiii, 236. On the Rate of Diffusion of Carbonic Oxide into the Lungs of Man.

13. Barcroft, J., et al., Phil. Trans. Roy. Soc., 1923, B-ccxi, 351. Observations upon the Effect of High Altitude on the Physiological Processes of the Human Body Carried Out in the Peruvian Andes Chiefly at Cerro de Pasco.

14. Harrop, G. A., Jour. A. M. A., 1923, lxxx, 1644. Relation of the Pulmonary Gas Diffusion Constant to Mountain Sickness.

15. Lundsgaard, C., and Shierbeck, K., Proc. Soc. Exp. Biol. and Med., 1922, $\mathrm{xx}, 151-167$. Studies on Lung Volume. IV. Investigations on Admixture of Air in the Lungs with Other Air.

16. Krogh, A., and Lindhard, J., Skand. Arch. Physiol., 1912, xxvii, 100. Measurements of the Blood Flow through the Lungs of Man.

17. Hartridge, H., and Roughton, F. J. W., Proc. Roy. Soc., 1923, B-xciv, 336. The Velocity with Which Carbon Monoxide Displaces Oxygen from Combination with Hemoglobin.

18. Barcroft, J., et al., Jour. Physiol., 1920, liii, 450. The Flow of Oxygen through the Pulmonary Epithelium.

Harrop, G. A., Jour. Exper. Med., 1919, xxx, 241. The Oxygen and Carbon Dioxide Content of Arterial and of Venous Blood in Normal Individuals and in Patients with Anemia and Heart Disease.

19. Himwich, H. E., and Barr, D. P., Jour. Biol. Chem., 1923, lvii, 363. Studies in the Physiology of Muscular Exercise. V. Oxygen Relationships in the Arterial Blood.

20. Gaisböck, F., Ergeb. d. Inn. Med. u. Kindh., 1922, xxi, 204. Die Polyzythämie. Morawitz and Denicke, Article on Erythremia in Mohr and Staehelin's Handbuch, 1925, iv, Pt. 1, 158.

Paltauf, R., Article on Polycythemia in Krehl and Marchand, Handbuch der allgemein. Path., 1912, ii, Pt. 1, 112.

21. Curschmann, H., Acta med. Skand., 1922, lvii, 228. Utber familiäre und konstitutionelle Polycythemia rubra.

Engelking, E., Klin. Monatsbl. f. Augenheilk., 1920, lxiv, 645. Ueber familiäre Polycythaemie und die dabei beobachteten Augenveränderungen.

22. Dallwig, H. C., Kolls, A. C., and Loevenhart, A. S., Am. Jour. Physiol., 1915, xxxix, 77. The Mechanism Adapting the Oxygen Capacity of the Blood to the Requirements of the Tissues.

23. Brown, G. E., and Giffin, H. G., Am. Jour. Med. Sci., 1926, clxxi, 157. Studies of the Vascular Changes in Cases of Polycythemia Vera.

24. Liljestrand, G., and Stenström, N., Acta med. Skand., 1925, 1xiii, 130 . Work of the Heart During Rest; Influence of Variations in Hemoglobin Content on the Blood Flow. 